\title{
Educación Musical. ¿Para qué?
}

\author{
M.Ed. María Jesús Zárate Montero
}

- ¿Profesor?, ¿profesor?- dijo Laura.

- -Si, dígame!-, le respondió su profesor, desde la seguridad de su escritorio, sin tan siquiera levantar los ojos del libro de historia de la música con el cual leía en forma confusa, a un somnoliento y aburrido grupo de sétimo año. Ese "sí, dígame", parecía más bien un tajante " ¿y ahora qué?, ¿no ves que estoy ocupado educándote?"

- ¿Es que quería preguntarle...?-Murmuró intimidada por el seco tono de voz y la fría y penetrante mirada de su profesor.

- ¿Qué cosa?, pero rápido que estoy ocupado-, gruñó su interlocutor.

-Es que quería preguntarle: ¿Para qué tenemos que asistir a clases de música?

El profesor frunció el seño, como cuando a alguien le colman la paciencia, resopló, miró a Laura fijamente a los ojos y antes de abrir la boca... sonó el timbre y de un salto desapareció la clase, sin darle tiempo a contestar, cosa que él agradeció profundamente.

Quizás esta sea una de las preguntas que más plantean los estudiantes a sus educadores musicales en los di- 
versos ambientes educativos donde la clase de música sea parte del currículo.

Y quizás la respuesta más común sea: porque es parte del plan de estudios, o simplemente porque sí.

En otros casos, es probable que existan algunos educadores que además de tener años de experiencia como docentes, cuenten con preparación universitaria y, de paso, dispongan de ese toque especial llamado vocación, que se animen a ofrecer una respuesta más convincente y motivante a sus alumnos.

Esta simple pregunta, que puede parecer muchas veces una necedad por parte de un estudiante subversivo, evidencia el deseo de dar un sentido a lo que se hace en esos ochenta o cuarenta minutos de clase. Por su parte, otros participantes del acto educativo que suelen preguntarse lo mismo son los administradores educativos, las maestras de preescolar, de primaria, los padres de familia e incluso los niños de estos entornos, cuando tienen que dejar sus juegos porque tienen que ir a la clase de música, que muchas veces no es tan agradable como lo esperan.

Puede que en un día de clases, los educadores musicales escuchen frases e interrogantes como estas:

- Otra vez, vamos a cantar el Himno Nacional!, ¿Por qué, si me lo sé desde que estaba en la escuela?, qué aburrido, siempre es lo mismo.

- ¿Y para qué tengo que tocar flauta si yo quiero ser mecánico?

- Y seguimos con el "Ta - Ta - tata - Ta"!, como si eso sirviera para tocar en la banda de rock que está haciendo un amigo mío.

- ¡Ay no, hoy nos toca oír música clásica!, y como siempre del tal Mozart, pero si el otro día el "profe" escribió el nombre de unos veinte de esos. 
Talvez surjan interrogantes más personales, como:

- ¿Por qué estudió música?, ¿Cuánto le pagan?

- ¿Cuánto tiempo tiene de estudiar música?, ¿Cuántos instrumentos sabe tocar?

-¿Cuál es su música favorita?, ¿Qué es lo que más le gusta de su trabajo?

-A mí me gustaría ser profe de música, ¿qué hay que hacer para lograrlo?

La lista de preguntas puede ser interminable y de hecho lo es, pero lo importante aquí no es qué preguntan y cuánto preguntan; el meollo del asunto es iqué responde el educador?, ¿estará realmente convencido de la importancia de su trabajo?, ¿será conciente acaso, de su papel como puente entre la cultura universal y la cotidianeidad de sus estudiantes?, ¿cómo se definirá así mismo: como un músico frustrado que da clases porque no le queda de otra, o como un educador que además de hacer y amar la música desea intensamente formar personas integrales, sensibles a la belleza y al arte, y en consecuencia amantes y críticos de su propia cultura?, ¿cuál de estas dos posiciones caracterizará su práctica docente actual y con cuál de estas dos posiciones le gustaría ser recordado por sus estudiantes en el futuro?

La respuesta a estas interrogantes la obtendrá cada educador que lea estas líneas después de un sincero examen de conciencia, en donde se cuestione ipor qué y para qué tiene un puesto como profesional en la sociedad?, ¿por qué y para qué las clases de música forman parte del currículo escolar tanto en Costa Rica como en casi todos los países del mundo?

Ahora bien, con el propósito de ofrecer algunas pautas que permitan guiar este proceso interior y brindar algunas luces para los actores antes mencionados que se cuestionan el quehacer de los educadores musicales en sus 
centros, a continuación se analizarán algunos aspectos que explican la importancia de la educación respecto a sus funciones en la sociedad y la forma en cómo la educación musical esta relacionada con los mismos.

En primer lugar, es necesario entender la cultura como el conjunto de elementos construidos por los miembros de una sociedad que además de definirla, le han permitido sobrevivir a lo largo de la historia, entre ellos se puede mencionar los conocimientos científicos, técnicos, prácticos, artísticos y espirituales, así como los bienes materiales producto de la interacción de estos conocimientos.

Dichos elementos, al ser establecidos por las sociedades les caracterizan y diferencian unas de otras, éstos pueden clasificarse como:

1. Universales, estos son los que definen culturalmente una sociedad en forma global y con los que están enteramente identificados la mayoría de sus miembros. Entre ellos se pueden citar el lenguaje, el estilo de vida (alimentación, vestido), el comportamiento socialmente aceptado, sus expresiones artísticas, entre otros, por ejemplo lo que diferencia al "tico" de otras culturas.

2. Especiales, son los que identifican a los diferentes grupos sociales o gremios que conforman dicha sociedad, es lo que se espera de los miembros de ese grupo, por ejemplo el comportamiento que se espera o caracteriza a un profesor de música y que es diferente de lo que se espera de un sacerdote o de un abogado, entre otros.

3. Alternativos, estos son intereses personales que surgen en contraposición a los dos anteriores, en consecuencia son excluidos socialmente ya que no son tolerados y en su lucha por ser reconocidos pueden originar conflictos intraculturales. Éstos con el paso 
del tiempo pueden llegar a convertirse en universales. Un ejemplo de los mismos es la lucha por la legalización del matrimonio entre parejas homosexuales, la cual ya es un hecho en algunas sociedades.

El segundo aspecto por analizar es la educación, conceptualizada ésta como un proceso permanente de perfeccionamiento, mediante el cual el ser humano aprehende los elementos que le permitirán comprender, valorar e interactuar tanto con los miembros de la cultura a la que pertenece, así como con los de otras culturas; y de esta manera poder proyectar y realizar una vida plena dentro de sus propias posibilidades.

Dicho proceso es posible gracias a la educabilidad que posee toda persona, la cual, además de ser la capacidad innata para educarse, como cualidad exclusivamente humana le permite recibir influencias y reaccionar ante ellas al elaborar estructuras espirituales, que le personalizan y socializan, de tal forma que puede adquirir conciencia de su naturaleza dual, tendencia tanto hacia el bien como al mal, y ser capaz de elegir libre y responsablemente entre ambos bandos.

Es por medio de la educación que las sociedades esperan formar los ciudadanos que éstas necesitan, conscientes de sus potencialidades y de la necesidad de optar por el bien común, supeditando sus instintos y emociones por debajo de la razón. Esto con el fin de lograr la supervivencia, el progreso cultural y su trascendencia. Sin embargo, es importante hacer hincapié en que el concepto de educación analizado hasta el momento es muy amplio, ya que involucra muchos procesos educativos que podrían dividirse en dos grandes grupos: los no escolarizados y los escolarizados.

La educación no escolarizada es el producto de la interacción con otras personas, la cual es permanente y 
complementaria a la escolarizada. Mediante ella los niños aprehenden, de sus padres y de las personas con quienes tienen contacto, elementos culturales tales como el lenguaje y los valores éticos y morales que formarán parte de su persona a lo largo de la vida.

En el caso de la escolarizada esta se puede definir como la formación intelectual y moral impartida a una persona, ordenada simultáneamente a la consecución de diversos fines. Ésta es la que hace referencia a los procesos educativos que se llevan a cabo en un centro de estudios público (considérese de preescolar, primaria, secundaria o universidad) perteneciente a un sistema educativo, establecido, financiado y en la mayoría de los casos controlado por un Estado; o bien privado que de cierta manera debe estar legitimado por el sistema educativo antes mencionado.

A través de ésta el Estado facilita a las personas en forma masificada y limitada el acceso a los elementos culturales antes mencionados, con el fin de formar buenos ciudadanos, capaces de incorporarse en forma productiva a la sociedad. De ahí que esté llamada a cumplir tres funciones:

1. Ser un medio socializador en el que se transmita la cultura y en el que se aprenda a convivir con otras personas.

2. Ser liberadora, puesto que a través del conocimiento el ser humano se libera de su ignorancia y se acerca a la verdad, a la belleza y a la felicidad, amén de poder llegar a desarrollar sus potencialidades en forma autónoma y responsable.

3. Ser iluminadora de su propia cultura; es decir, que sea capaz de promover el pensamiento crítico, que genere los cambios culturales que necesita, pero que no siempre desea, una sociedad para mejorar las condiciones de vida de todos sus miembros, por ejemplo la erradicación del trabajo infantil. 
De lo anterior surge como tercer punto, la necesidad de contar con personas especializadas en el conocimiento, la selección, la transmisión y, por qué no, de la transformación de la cultura, es decir, personas que participen de diversas maneras en el fenómeno educativo, ya sea investigando y reflexionando acerca de su naturaleza con el propósito de describirlo y explicarlo; o bien como protagonistas del mismo, siendo este el caso del educador, cuyo compromiso social, personal y profesional es, además de ser un profundo conocedor y transmisor de su cultura, y en forma más específica de su campo de estudio, un incansable protagonista de las transformaciones culturales que la época actual amerita, tanto con sus conocimientos y experiencias como con sus producciones intelectuales.

Es a partir de estos tres puntos que se puede sugerir la tan esperada respuesta a la pregunta generadora de esta reflexión: ¿qué justifica la presencia de la educación musical como parte del currículo escolar?

Pues bien, uno de los elementos culturales que puede considerarse como universal, especial o característico de un grupo social e incluso alternativo son las artes, las cuales son actividades que representan la visión de mundo, la realidad, los sueños y las esperanzas de las distintas sociedades que conforman la humanidad, su principal función consiste en reforzar, extender, iluminar, transformar y en última instancia, hacer la vida más digna de ser vivida.

La música, por su parte, es el arte de combinar los sonidos para expresar diferentes pensamientos o sentimientos. Es tan particular como su autor y la cultura a la que pertenece, pero tan universal como los mismos ideales humanos. Esto por que aunque las creaciones de un compositor específico, representan su interpretación de la realidad y los elementos muy propios de su cultura (características musicales, lenguaje, valores, espiritualidad, visión de mundo, 
problemáticas sociales), la obra en sí al seducir al oyente hace que éste la constituya como parte de él, como una nueva voz propia que le permite expresar su mundo interior y su particular manera de vivenciar, interpretar y recrear la realidad circundante, lo cual le hace sentirse parte de algo y cómplice de las ideas, sentimientos y sueños de otros, sintonizándose con ellos en una frecuencia invisible, pero que puede ser comprendida cuando se escuchan dos o más voces cantando como si fueran una sola.

Su belleza y mensaje, al fundamentarse más en el sonido que en la palabra, le hace una de las expresiones artísticas más representativas e influyentes de una sociedad, puesto que es capaz de trascender la frontera cultural del idioma. De ahí que sea capaz, también, de influir en el ser humano en todos los niveles: biológico, fisiológico, psicológico, intelectual, social y espiritual.

Los investigadores Makoto Iwanaga y Don Campbell, coinciden en que la música es capaz de producir notables cambios fisiológicos en el organismo, entre los más importantes, la música acelera o retarda las principales funciones orgánicas: frecuencia cerebral (relacionada con las ondas cerebrales haciéndolas más lentas y uniformes, lo cual influye en el estado de ánimo y la conducta en general de las personas), circulación (ritmo cardíaco y presión arterial), respiración, digestión y metabolismo; incrementa o disminuye el tono, la energía y coordinación muscular; modifica el sistema inmunitario; altera la actividad neuronal en las zonas del cerebro implicadas en la emoción, e incrementa la resistencia para el trabajo y para las actividades de alto rendimiento, entre otros.

Por su parte, la musicoterapeuta Serafina Poch Blasco, explica que en la parte psicológica, la música puede despertar, evocar, estimular, robustecer y desarrollar diversas emociones y sentimientos, generando seguridad, bienestar 
y placer, lo que ayuda a la catarsis y a la sublimación. También, puede traer a la memoria olores y colores, así como modificar el estado de ánimo del oyente y su percepción del espacio y del tiempo. Suscita, además, el placer estético y mueve a la reflexión; incita y favorece la expresión de uno mismo e induce a la colaboración intergrupal y al entendimiento cultural. A nivel intelectual, facilita el aprendizaje al desarrollar la capacidad de atención, la imaginación y la creatividad; estimula la memoria a corto y largo plazo y desarrolla el sentido del orden y análisis. También ejercita la inteligencia, ya que favorece el uso de varios razonamientos a la vez, al percibir diferenciadamente sus elementos, y sintetizarlos en la captación de un mensaje integrado, lógico y bello.

Como terapia, la musicoterapeuta Juliette Alvin, la recomienda para el tratamiento de dolencias como la hipertensión arterial, estados de ansiedad, depresión y estrés, alteraciones del sueño y en la rehabilitación de pacientes psicóticos, de niños autistas y de adolescentes con trastornos del comportamiento.

Sin embargo, si es mal utilizada puede, de igual manera, generar efectos negativos, en especial en los niños y los jóvenes. La música, entonces, puede enfermar el cuerpo y la mente de diferentes maneras, por ejemplo, al ser escuchada a intensidades excesivas, así como los mensajes que pueda transmitir.

En el primer caso, es importante considerar que la exposición constante y por largos periodos a música estridente o a ruidos que sobrepasen el nivel de decibeles (dB) considerado peligroso para la salud (más de $85 \mathrm{~dB}$ ), pueden generar problemas de concentración y atención, reacciones de estrés, cansancio y alteración del sueño y más peligroso aún, ocasionar diferentes problemas auditivos que conduzcan a la eventual pérdida de la audición a edades 
muy tempranas; entre ellos, la hipoacúsia (disminución de la capacidad auditiva), la hiperacúsia (audición superior a la normal, relacionada con la algiacúsia, sensación dolorosa ante la presencia de un sonido cuya intensidad no alcanza el umbral del dolor en individuos normales) y los acúfenos, también llamados tinnitus, éstos pueden ser de frecuencias agudas (pitidos) o graves (zumbidos), temporales (se suelen apreciar más por la noche, pues es menor el ruido ambiental) o permanentes, presentarse de forma aislada o acompañando a múltiples enfermedades, tanto del oído externo, medio o interno.

Respecto a los mensajes presentes en las canciones, en especial aquellas de corte comercial, éstos pueden estar relacionados con temáticas tales como: drogas, suicidio, violencia, delincuencia, pasiones desenfrenadas, expresiones soeces y de doble sentido, entre otros.

Este tipo de música resulta ser entonces un objeto de consumo más, puesto que es creada para mover masas y generar ganancias, por lo que está dirigida a quienes carecen de criterio para criticarla o valorarla como arte; de ahí que su presencia es casi permanente en los medios de comunicación masiva, medios de transporte público, centros comerciales, lugares concurridos y actividades multitudinarias.

Al ser música con letras y ritmos pegajosos, es fácil de asimilar y de promover, e incluso de heredar, por lo que no es de extrañar que el interés por la misma se transmita familiarmente. Lo anterior no puede ignorar la necesidad de educar musicalmente a las personas, en primer lugar para aprovechar los beneficios de la música en el desarrollo integral de la persona y, en segundo lugar, cuidar su integridad y salud mental, espiritual y física.

Es aquí donde entra en juego la importancia de la educación musical, debido a que al educar la sensibilidad 
para apreciar la belleza, los niños y jóvenes podrán adquirir los criterios para decidir qué tipo de escuchas quieren ser y con qué tipo de música desean identificarse.

La misma, puede definirse entonces, a partir del concepto de educación antes mencionado, como el proceso mediante el cual las personas se acercan a la música, la conocen y aprehenden de ella y con ella los aspectos relacionados con su naturaleza, constitución, estructura, composición, representación, interpretación, ejecución, efectos, disfrute, transmisión, presencia y relevancia como elemento cultural de la humanidad.

Así como cada grupo cultural se preocupa de transmitir sus conocimientos científicos, tecnológicos, médicos, filosóficos, teológicos, axiológicos e intelectuales, se preocupa por heredar, también, lo mejor de sus bienes artísticos, por eso la enseñanza y el aprendizaje de la música ha estado presente y debería seguir estando en todas las sociedades.

Es decir, la educación musical es parte de la cultura y, por lo tanto, todas las personas tienen derecho a ser educadas musicalmente, en especial en su infancia y adolescencia; ya sea cantando, bailando, ejecutando un instrumento musical, escuchando o leyendo sobre la música. Ahora bien, al igual que la educación en general, la educación musical puede o no ser escolarizada, esto quiere decir que debe ser parte de la educación que se brinda a nivel familiar y también debe ser parte del currículo escolar.

Esto porque, se sea consciente o no, desde el momento en que los padres rodean con música a sus bebés, están acercándolos a ella y están inculcando en sus hijos sus gustos musicales. Conforme crezca el niño, asimilará las expresiones musicales que formen parte de su entorno y las incorporará a su visión de mundo que más adelante le servirá de base para el posterior aprendizaje musical sistemático, general y consciente que realice en los centros educativos a los que asista. 
Dichos conocimientos previos, también serán importantes, si además tiene la oportunidad de iniciar el aprendizaje de un instrumento musical en forma más especializada. Es por esa razón que Zoltan Kodály, pedagogo musical húngaro, consideraba que la educación musical del niño debía iniciarse "nueve meses antes del nacimiento de su madre".

Ahora bien, la educación musical, además de estimular la sensibilidad y musicalidad de las personas, puede ayudar a aprehender otros elementos culturales que forman parte de la educación escolarizada, ya que su influencia y práctica estimulan el desarrollo cerebral, favoreciendo las conexiones de ambos hemisferios, lo que permiten una mayor capacidad para procesar, producir y expresar conocimiento, fortaleciéndose así la creatividad y la capacidad para aprender.

Los beneficios de una adecuada educación musical se pueden generar y percibir, en forma más consciente, desde la educación preescolar y son la base para los aprendizajes de los niveles superiores, en este sentido es fundamental que la educación musical se caracterice por ser sistemática, constante y estratégicamente diseñada, planeada, enseñada y evaluada, ya que de esta manera se aprovecharán y darán continuidad a los conocimientos musicales previos de los estudiantes.

Así, la enseñanza musical puede contribuir en el desarrollo psicomotor, lingüístico, cognitivo, emocional, espiritual, social y afectivo. Las diversas actividades musicales, en especial con los niños en edad preescolar y escolar, como la apreciación y la lectoescritura musical, el canto acompañado con gestos y movimientos, los bailes, los juegos o la ejecución instrumental, individual y en conjunto:

1. Potencian la capacidad del cuerpo para percibir e interpretar la música, colaborando con el ordenamiento 
psicomotriz al trabajar las posibilidades sonoras y de movimiento del propio cuerpo, es decir su orientación respecto a los demás, a un espacio o a un tiempo, lo que ayuda a anticipar, organizar y sincronizar el movimiento.

2. Perfeccionan los sentidos y, a la vez, realizan una función de carácter diagnóstico desde el punto de vista sensorial.

3. Promueven el desarrollo de funciones intelectuales como la atención, la memoria, el análisis, la concentración, la interpretación de códigos y símbolos, el pensamiento lógico, la resolución de problemas, la elaboración de conceptos, el desarrollo del lenguaje oral y la comprensión del lenguaje musical.

4. Ayudan en el desarrollo auditivo y al tratamiento de problemas del lenguaje, esto porque con las canciones se adquiere vocabulario y se trabajan la expresión, entonación, articulación y vocalización; además que pueden ser una excelente herramienta en la fijación de conceptos (números, partes del cuerpo, letras, lugares, objetos).

5. Educan y disciplinan la autonomía, el rendimiento, el carácter y la constancia.

6. Mejoran la autoestima, facilitan la comunicación, la exteriorización de emociones, la empatía, las relaciones sociales y la vivencia de valores, como la estimación del esfuerzo individual y colectivo, el respeto, la solidaridad y el trabajo en equipo.

7. Desarrollan la sensibilidad y gusto por lo bello.

8. Estimulan y refuerzan la imaginación y la creatividad.

9. Desarrollan la autocrítica y el pensamiento crítico, respecto al entorno acústico, artístico y social, por ejemplo, al analizar el papel de la música en la historia, los 
usos y abusos actuales de ésta y al cuestionar los mensajes que en este momento se pretenden transmitir mediante la misma.

10. Promueven la valoración del silencio y el rechazo hacia el exceso de ruido.

Retomando parte de lo anterior, para lograr estos y otros aspectos, es realmente indispensable que la educación musical se caracterice por ser "sistemática, constante y estratégicamente diseñada, planeada, enseñada y evaluada", es decir no puede ser un conjunto de ocurrencias o actividades improvisadas sin conecte o justificación alguna, que tengan a fin de cuentas, el propósito el entretener y pasar el tiempo. Dicha descripción es paradójicamente muy similar a la que se vive en muchos centros educativos y que en gran medida ha contribuido en la concepción actual que muchos padres, administrativos y docentes tienen sobre esta materia y quien la enseña.

Por esta razón es necesario aclarar que la educación musical en Costa Rica, al formar parte del currículo, tanto para primaria como para secundaria, está organizada en diferentes áreas (canto; lectoescritura, creación y ejecución instrumental; cultura y apreciación musical; ecología acústica; y movimiento y expresión corporal) las cuales organizan y distribuyen los contenidos y actividades musicales por desarrollar de acuerdo con las capacidades y madurez cognitiva de los estudiantes, por lo que, al igual que en las otras materias, la cantidad y calidad de la información que se asimilará, así como el grado de dificultad de las actividades que se realizarán se incrementará año con año.

En cuanto a la planeación, enseñanza y evaluación estratégicas de la música, estas actividades son responsabilidad de los educadores especializados en este campo, quienes deben caracterizarse, entre otros aspectos, por conocer, 
amar y vivir la música, ser conscientes de la importancia de la educación musical en el desarrollo integral de las personas, estar musical y pedagógicamente preparados de la mejor forma posible para asumir dicha responsabilidad, estar interesados y ser perseverantes para continuar educándose en su carrera y, sobretodo, sentir la vocación por educar, por ayudar a los niños y jóvenes a ser mejores personas mediante el disfrute y la práctica musical.

Es triste pensar que si la música es tan importante para las personas y la enseñanza y aprendizaje de la misma lo es aún más, ¿por qué hay un alto porcentaje de estudiantes que considera la clase de música como un campo de batalla en el que, el principal objetivo es mortificar y hacer perder la paciencia del que está a cargo? Me atrevo a pensar que es más por la actitud del docente cuándo enseña que por los conocimientos en sí; esto quiere decir que el primero en valorar la presencia de la música en la educación de las personas debe ser el mismo educador, y que de nada le servirán su talento, conocimientos, títulos y discursos si no es capaz de demostrar con su actitud lo importante que es la música y sus alumnos para él o ella.

Si la música puede hacer que miles de personas se reúnan en forma voluntaria para convivir y vibrar en forma conjunta durante algunas horas, ¿por qué cuando se dice "clases de música" en los ámbitos educativos mencionados muchas veces se arruga la cara, y más de un estudiante tiene un repentino dolor de cabeza o simplemente huye?, ¿será acaso que los docentes en música hemos perdido nuestra magia para seducir a nuestros estudiantes?, ¿será que nos preocupamos demasiado por cumplir lo que estipula el plan de estudios y por preparar los exámenes para que los revise y apruebe el comité de evaluación y olvidamos que lo que realmente importa es el guiar a nuestros estudiantes para que conozcan la música, por medio de sus diferentes géneros, 
para que partir de sus valores, conocimientos y gustos desarrollen una posición ante lo que escuchan, considerando qué tanto les enriquece personalmente?

Nuestros estudiantes no son adultos en miniatura, son personas en formación, que tienen sueños pero que también enfrentan frustraciones, temores y problemas familiares y sociales. Al tener acceso a diferentes medios de comunicación y al Internet, son más conscientes de las barbaridades que el ser humano comente contra otros, con la naturaleza y con él mismo. Son niños y jóvenes que por muchas razones se les exige, de una u otra manera, que crezcan y maduren rápido, convirtiéndose en adultos jóvenes ansiosos de poseer éxito, reconocimiento profesional y amor; de tener estabilidad económica, de comprar cosas y más cosas; pero vacíos espiritualmente, con una gran facilidad para estar en crisis (a los veinte, a los veinticinco, a los treinta...). Entonces, ¿cómo se puede estar tan tranquilo en un aula? Conformándose con que canten y de mal modo el Himno Nacional, que identifiquen algunos símbolos musicales o que toquen algunas melodías con la flauta dulce.

Es necesario que el educador musical reflexione y se convenza a sí mismo, que, lo crea o no, su trabajo dejará huellas en sus estudiantes, por lo que está llamado a replantear su práctica docente, lo que enseña, las estrategias que usa y el modo en cómo lo hace.

Quizás alguien me cuestione, iy qué pasa soy yo trato de ser buen músico y educador pero me siento sólo en esta aventura?, ipor qué siento que toda la responsabilidad me la han dejado a mí?, ¿por qué no se dan cuenta que tengo los conocimientos, el deseo y la voluntad para hacer mi trabajo, pero todos los días tengo que lidiar con limitaciones que poco a poco están minando mis nobles intenciones? Sí, es muy probable que al hacer unos minutos de 
silencio se escuchen en nuestra mente las voces muchos educadores planteando estas y otras interrogantes.

Por eso, otro aspecto que es vital para lograr una adecuada formación musical es el contar con los materiales y recursos, y además con el apoyo de los otros actores sociales involucrados en el proceso educativo, es decir, de los familiares, administradores y docentes, que están en contacto con el educador musical, porque como ya se comentó, la educación musical se inicia y se complementa en el hogar, por lo que las sugerencias de los padres y la valoración del trabajo del educador son excelentes aliados para que los alumnos interioricen la importancia de lo que aprenden y hacen en la clase de música. En pocas palabras: todos los miembros de una sociedad comparten la responsabilidad de heredar la música, que le hace única, a sus nuevas generaciones, apoyados por supuesto en la labor de los que se especialicen en ello.

De este modo, quienes trabajan con niños en edades preescolares y la primaria también están llamados a educarse musicalmente, tanto para su desarrollo personal como para poder aprovechar al máximo la música como herramienta didáctica en el desarrollo de sus clases. No están obligados a ser expertos pero si a estimular en sus estudiantes el gusto por las diferentes expresiones musicales, tanto nacionales como internacionales $y$, a generar en ellos criterios para analizar la calidad musical del repertorio que escuchan a fin de desarrollar su sensibilidad y sentido estético.

En el caso de la secundaria, al ser tan marcada la separación entre las materias, sería de gran provecho para los estudiantes que los docentes traten de integrar el currículo; es decir, que mediante el diálogo, el trabajo en equipo, la búsqueda y realización de actividades musicales se complementen y enriquezcan los contenidos estudiados en las diferentes materias. 
Más importante resulta aún, que los mismos docentes de música se unan, formen equipo y trabajen en armonía, ayudándose mutuamente a mejorar las áreas débiles de cada uno y de igual manera, es valioso también, el colaborar y compartir con colegas de otras instituciones, puesto que si la música facilita las relaciones sociales entre los estudiantes, entonces, no se justifica la individualidad y el egoísmo entre quienes promueven y se desempeñan en su enseñanza.

$\mathrm{Ni}$ mucho menos alegar ignorancia o falta de oportunidades para educarse y perfeccionarse como músico y educador, en este sentido los institutos de formación musical, las universidades y las nuevas tecnologías de la información y la comunicación pueden ayudar a profesionalizar y complementar la formación alcanzada. Es cierto que el educarse en forma permanente implica un esfuerzo personal y una inversión económica y de tiempo extra; sin embargo, los primeros beneficiarios son los mismos educadores y, posteriormente, sus estudiantes y compañeros docentes.

Entonces, estimado lector, querida Ana y no muy convencido profesor, al concluir la presente reflexión podría decirse que la educación musical debe formar parte de la educación, tanto la escolarizada como la no escolarizada porque la música es:

1. Un elemento cultural que identifica a los diferentes grupos sociales que interactúan en nuestro planeta. Como tal, refleja parte de la visión de mundo con la que sus compositores y ejecutantes tratan de interpretar y analizar la realidad en la que viven y que, al estar presente a lo largo de la historia, facilita la comprensión de ideas y acciones de quienes nos precedieron.

2. Una construcción individual y social, cuyo mensaje puede influir de diferentes maneras en las personas, ya sea en forma biológica, fisiológica, psicológica, social y espiritual, tanto positiva como negativamente. 
3. Un arte, que debidamente enseñado, aprendido y practicado es de gran valor para el desarrollo integral de las personas, debido a que al estimular la actividad cerebral facilita y refuerza el aprendizaje, capacidad que permite al ser humano potenciar su educabilidad a fin de aprehender los elementos culturales que ayuden a formarse, integrarse e interactuar dentro del grupo social al que pertenece, y a valorar y respetar las diferencias de los demás.

4. Un excelente medio para reflexionar sobre nuestras actuaciones, compartir emociones, manifestar sentimientos, convivir y disfrutar con quienes nos rodean de las otras expresiones artísticas y los aspectos hermosos de la vida.

Y a través de la educación musical se aprende a vivir, comprender, interpretar y saborear la música, incorporándola como parte esencial de la vida con el propósito de llegar a ser personas más sabias, bellas y felices.

Finalmente, es importante recalcar que el educador musical, por medio de la musicalización y sensibilización de sus estudiantes, está llamado a contribuir en la educación integral de los mismos. Eso sí, sin olvidar que sus clases no deben ser tan técnicas como la matemática ni tan prácticas como los estudios sociales, si se definen desde el punto de vista de los intereses de Habermas, sino, que deben tener un poco de ambas y, además, caracterizarse por promover en los estudiantes, entre otros aspectos, el gusto por la vida, la belleza, la felicidad y la verdad, así como la autonomía y la criticidad para aprehender los valores culturales que realmente les ayudarán a ser personas íntegras.

Por eso, querido lector, si usted es educador musical no espere a que le pregunten para qué sirven sus clases, haga de ellas un lugar especial, que se salga de la rutina y donde, 
además, de hacer y aprender música, sus estudiantes puedan sentirse personas valiosas y amadas.

Aproveche al máximo que su especialidad no está sujeta a una prueba estandarizada con carácter de promoción y conviértala en el momento más esperado de la semana, donde sus estudiantes le saluden entusiasmados y con la mirada brillante, como la de los niños pequeños cuando piden que se les compre el helado de su sabor favorito: iy hoy qué vamos a hacer, qué vamos a escuchar, qué vamos a aprender?

Ofrézcales un espacio para canalizar sus energías, para relajarse, para estar en paz, y sobretodo, hágales saber que, con esfuerzo, constancia y paciencia, pueden llegar a ser mejores; incluso que aunque sus capacidades musicales sean algo limitadas, en el mundo se necesitan tanto las personas que escriben e interpretan música como aquellas que la escuchen y la aprecien, por lo que todos somos necesarios.

Si bien es cierto, aunque nuestro trabajo como educadores musicales puede parecer muchas veces tan pequeño y simple como una nota musical, es tan valioso como las miles de notas musicales que forman parte de las más grandes obras maestras. Quizás, el darle sentido a algo tan simple como la clase de música puede ser la base para que nuestros estudiantes, en un futuro no muy lejano puedan dar sentido a su existencia en el mundo.

\section{REFERENCIAS BIBLIOGRÁFICAS}

Fermoso, P. (1981). Teoría de la Educación. México, Trillas. Leiva, M. y Matés, E. (2002). La Educación Musical: algo imprescindible. Recuperado el 10 de enero de 2007, de http:/ /www.filomusica.com/filo33/educacion.html. 
Luckert, F. (2001). Al reencuentro del ser, la creatividad y la emoción en el aprendizaje musical. Ponencia presentada en el Tercer Encuentro Internacional de Educación Musical.

Márquez, E. (2004). Los valores en la educación musical. Recuperado el 14 de abril de 2005, de http://musica.rediris.es/ leeme/revista/marquez.htm.

Pascual, P. (2002). Didáctica de la Música para Primaria. Madrid: Pearson Educación, S.A.

Pascual, P. (2006). Didáctica de la Música para Educación Preescolar. Madrid: Pearson Educación, S.A.

Rodríguez-Quiles, J. (2003) ¿Es necesaria una Educación Musical para todos?. Recuperado el 18 de diciembre de 2006, de http://musica.rediris.es/leeme/revista/rodriguezquil.htm

Soto, G. (2003). La música: un factor de evolución social y humana. Recuperado el 13 de enero de 2007, de http:// www.redcientifica.com/doc/doc200209150300.html

Swanwick, K. (1991). Música, pensamiento y educación. Madrid, España. Ediciones Morata.

Vargas, A. (2002). Música en la educación primaria. Colección Pedagógica Formación Inicial de Docentes Centroamericanos de Educación Primaria o Básica. Coordinación Educativa y Cultural Centroamericana (CECC). Cartago: Impresora Obando.

Vilar, M. (2004). Acerca de la educación musical. Recuperado el 17 de diciembre de 2006, de http://musica.rediris.es/leeme/revista/vilarm.pdf 